\title{
014 IMMISCIBLE WAG INJECTION IN THE FENSFJORD FORMATION OF THE BRAGE OIL FIELD
}

ARNE SKAUGE and EIRIK A. BERG Norsk Hydro ASA, 5020 Bergen. Norway

\begin{abstract}
An immiscible gas, WAG injection was initiated in the Fensfjord reservoir of the Brage Field late 1994. Two injection wells initially applied cyclic injection of gas and water. The pulse length of gas injection was about three months, and the W/G ratio has been close to 1:1. Gas breakthrough was observed after three months, according to expected breakthrough time from simulation studies. The WAG injection has later been expanded to six injection wells.
\end{abstract}

Studies of the reservoir behavior have shown that several parameters influence the GOR development including, pressure maintenance strategy, perforation interval, permeability distribution and layer geometry. Use of tracer injection have been useful in understanding the reservoir performance and in updating the geological model. Tracer breakthrough gives an early detection of breakthrough of injected gas and gives important information about the connection between individual producers and injectors. Extensive use of tracers has proved to be an effective tool in monitoring the movement of injected fluids. Numerical methods for tracer diffusion control are discussed and compared.

\section{Introduction}

WAG injection has been increasingly applied in oil reservoirs on the Norwegian sector of the North Seal-4. The Brage field ${ }^{4}$ is located $100 \mathrm{~km}$ west of Bergen, and is a shallow marine deposit, where the Upper Jurassic sediments are defined by upward coarsening silt and sandstone successions. Details about the geological history of this reservoir and the causes of the extensive faulting and vertical shifts due to uplift of the Brage Horst are described in reference 4.

The Fensfjord reservoir, of the Brage field, is a highly stratified reservoir with typically layer thickness of less than $5 \mathrm{~m}$ and average permeabilities varying from less than $1 \mathrm{mD}$ to more than $200 \mathrm{mD}$. These layers, having thickness of less than $5 \mathrm{~m}$, are even further stratified by large permeability contrasts, discontinues high permeability streaks and calcite layers. Core material and production information so far show thin high permeability stringers that play a significant role both for injection and production performance.

The Fensfjord reservoir started a two-well WAG pilot late 1994. Combined water and gas injection have later been extended to 6 injection wells. The main objectives of the WAG strategy is to give pressure support, improve vertical sweep and improve recovery of attic oil

The paper contains field observations, core analysis data, WAG strategy and further plans. Especially, we emphasize the information obtained from reservoir monitoring by tracers. The tracer injection plan and data obtained from backproduction of tracers are discussed. Tracers have been modelled by different numerical methods with the objective to reduce the numerical dispersion. Tracer simulations with a solution gas approach have shown to give comparable results to more refined numerical methods for dispersion control available in black oil simulations.

\section{Results and discussions \\ WAG history}

Currently 6 wells are involved in the plans for WAG injection, A-12, A-17, A-18, A-26, A-28 and A-16. Generally, only one well apply gas injection at a time, while the other injection wells inject water. A permeability and porosity $\log$ of the A-26 injector are shown in Figure 1. Large permeability contrasts are shown and the upper high permeable layer accounts for $95 \%$ of the injectivity. The gas injection rate has been about $600,000 \mathrm{Sm}^{3}$ equivalent to $3800 \mathrm{Sm}^{3}$ injection rate for water. The water injectivity is limited because of several factors like low water relative permeability, generally low permeability and near-well restrictions, and the injection rate has seldom been above 
$2500 \mathrm{Sm}^{3}$. Thus, the gas injection improves pressure maintenance compared to water injection. At the Brage field, tracers have been added to the water and gas phases during the WAG injection into the Fensfjord Formation.

\section{Fluid flow properties}

Waterflooding have been extensively investigated by many special core analysis studies describing the variation in rock properties for different areas and vertical layers of the Fensfjord reservoir. Gas - oil relative permeability and residual oil saturation have been calculated from long core gas injection and centrifuge oil drainage. Comparing oil recovery from waterflood and gas injection on the same long core from Fensfjord showed remaining oil of 32.4 and 33.4 saturation units (s.u.). The final residual oil saturation from gas injection may be significant lower as oil was still produced at a low fractional flow of 2 per cent when the experiment was stopped after 2.5 pore volume.

More special experiments have been performed to investigate further oil mobilization during three-phase flow and generate input data for simulation of WAG fluid flow of the Fensfjord reservoir. The experimental study includes both primary gas injection and waterflood, and also oil mobilization after primary processes. Gas injection after the primary waterflood shows an additional oil production, while waterflooding after primary gas only gave very small change in the remaining oil saturation. Slug injection of gas and water gave a remaining oil saturation of 24 s.u. after injecting only 2 pore volumes.

The waterflood results show a low endpoint water relative permeability and little oil production after water breakthrough. Gas injection after waterflood shows a reduced gas mobility compared to primary gas injection. Indicating that three-phase gas relative permeabilities are different from two-phase gas relative permeabilities. Input rock relative permeability data were generated for base case (no relative permeability hysteresis) WAG simulations. Relative permeability hysteresis for gas and water phases are also calculated from the secondary gas and secondary / tertiary water displacements, Figure 2 . Gas trapping by increasing water saturation gave a Land constant ${ }^{5}$ of 1.8 for the Fensfjord core data. The effect of trapped gas on remaining oil have been analysed and shows as an example that 10 s.u. trapped gas will reduce the remaining oil by 5 s.u. The importance of relative permeability hysteresis on immiscible WAG performance have been shown through variation with core analysis properties ${ }^{6}$ and has been described by different modeling approaches ${ }^{7,8}$. However, field performance show that net reduction in residual oil saturation due to WAG, is low because of water and gas segregation within flow units. Gas flow up into thin high permeable layers and water is slumping downwards. As such, no reduction in gas mobility is observed during successive WAG cycles.

\section{Reservoir monitoring by tracers}

The objectives of tracer injection for monitoring of the WAG process have been to use breakthrough time and tracer production / injection history to give a better understanding of dynamic reservoir behavior and support upgrade of the static reservoir model. In addition information about how residual saturations and relative permeability may be affected by the WAG process could be obtained. The gas and water tracers used have been selected because of low partitioning to other fluid phases and analytical detection level. Both chemical and radioactive tracers have been applied. The physical properties of most of the tracers we have used are given in references 9 and 10 . The injected tracers are summarized in Table 1.

\section{Tracer results}

The first gas tracer was injected in December 1994, and most gas tracers have currently been produced in several production wells. Because of page limitation, we will concentrate on the gas and water tracer response of the A-26 injector, being one of the two first WAG injectors, and producer A-23 being the nearest to A-26. The tracer injection history of A-26 is first water injection only tagged by the seawater. At the first part of gas injection a chemical tracer Chemical $\mathrm{SF}_{6}$ was injected in the gas stream, 19 Dec. 1994. Tritiated water was injected in water, 10. May 1995, and the chemical tracer perfluormethylcyclopentane PMCP was injected in gas, 27 Nov. 1995.

Measurements in production wells have so far detected tracer responses as shown in Table 1. Tracer performance has also been modelled by using the ECLIPSE numerical reservoir simulator with results as presented in Table 1 and an example of the reach of the gas tracer $\mathrm{SF}_{6}$ at different time is shown in Figure 3. The gas breakthrough in A-23 could not be observed from the GOR measurements, but was easily detecled from the tracer analysis.

Tracer velocity has been calculated from the time between injection and observed tracer in the production well divided by the distance between the wells. Results are shown in Figure 4 . The correct tracer velocity is even higher as the data should by corrected for the delay due to partitioning to other fluid phases ${ }^{9}$ and adsorption on or ion 
exchange with the rock surface. An example of corrected gas tracer is that $\mathrm{SF}_{6}$ velocity should by multiplied by a factor of 0,67 to account for partitioning to the oil phase.

\section{Tracer modeling}

The full field model and a simplified sector model have been used to test numerical methods for tracer modeling. The example used gas tracers from the first two WAG injection wells; wells A-18 and A-26, and observed tracer breakthrough in production wells A-23 and A-25. In this study, the ECLIPSE reservoir simulator with a tracer tracking option has been used to simulate the WAG process. In ECLIPSE there exist two methods for reduction of numerical diffusion when using the tracer tracking option. Both methods assume that no mass transfer effects occur, which means that no dissolved gas is allowed in the oil phase and no vaporized oil is allowed in the gas phase. Here, only a short description is given, but the methods are more thoroughly explained in reference 11 .

The flux limited transport scheme is a higher-order method for reduction of numerical dispersion of the tracer. It uses a limiting function to prevent unphysical oscillations near sharp fronts and updates the tracer concentrations explicitly using a mini time step ${ }^{11}$. The cascade algorithm is an algorithm that calculates the tracer concentrations in flow order. Explicit tracer concentrations are used in cells with a phase throughput ratio less than one during a time step. If the throughput ratio is greater than one, the tracer concentrations cascade on to the downstream cells.

Only the gas tracers have been evaluated in this study, as breakthrough had not been observed for any of the water tracers at the time of this study. The results in Figure 5 show that the choice of tracer tracking option has minor effect on the breakthrough time for the earliest injected tracer, SF6. Using tracer options that reduce numerical diffusion delays breakthrough for the tracer PMCP, especially for well A-25 which has the longest response time. The sharpest concentration profiles and largest maximum concentration values were obtained in the simulations where the flux limiting scheme was applied.

The cascade algorithm seemed to be very sensitive to time step size, giving poor material balance, while the time step sensitivity is quite small for the other tracer options. Grid refinement reduced numerical diffusion, and the effect of grid refinement is about the same for all tracer options. For further simulation of tracer tracking the default model is preferred because of the advantage of dissolved gas compared to the methods for reduced numerical diffusion.

\section{WAG strategy and further plan}

The gain of gas injection is, as mentioned earlier, improved pressure maintenance, but in addition a better sweep in anticipated. The material balance calculation indicates that about $50 \%$ of the injected gas are stored in the reservoir. Figure 6.shows a comparison of WAG simulation and gas material balance based on production data. It is shown that at least $03.2 \mathrm{MSm}^{3}\left(0.42 \mathrm{MRm}^{3}\right)$ oil can be attributed to the WAG injection. Incremental oil production by the current WAG concept is expected to be about $1.1 \mathrm{MSm}^{3}$ with the current concept of injecting gas into one well at the time until year 2002. Simulation studies have shown that extension of WAG in Fensfjord to the full length of the production period may give an additional improved oil recovery by WAG of about $2,5 \mathrm{MSm}^{3}$. Even higher recovery could be obtained both by prolonging the time for WAG injection and by increasing the gas injection to two gas injectors operating simultaneously. The length of the WAG cycle does not affect the final oil recovery in these simulations performed with the full field model.

\section{Conclusions}

WAG injection shows early gas breakthrough as expected from the field simulation studies. However, the production data indicates that a large amount of the injected gas is stored in the reservoir, and gives less gas for export. No negative effects on field performance have been observed.

Core analysis data indicates a possibility for improved microscopic displacement efficiency in gas invaded and three-phase flow areas compared to water injection.

Tracers have proved to be an effective tool for reservoir monitoring of the WAG process. Tracer tracking with a standard approach (ECLIPSE default model) was preferred because of the advantage of dissolved gas and little hange of the gas breakthrough was observed compared to methods for reduced numerical diffusion.

Material balance calculation, field observations and simulation studies show an improved oil recovery by immiscible WAG injection in the Fensfjord reservoir. 


\section{Acknowledgement}

We acknowledge Norsk Hydro and the Brage license partners for permission to present this paper. Anne Grethe Hansen is acknowledged for her contribution in analysis of different numerical tracer modeling approaches. We also acknowledge all colleagues in Norsk Hydro who contributed to this study.

\section{References}

1. Hinderaker, L. et al, "IOR Resource Potential of Norwegian North Sea Sandstone Reservoirs Proceedings, 6th European Symposium on Improved Oil Recovery, Stavanger, May 1991, Vol. 2, 957-966.

2. Dalen, V., Instefjord, R, and Kristensen, R.: "A WAG Injection Pilot in the Lower Brent Formation at the Gullfaks Field", 7th European IOR Symposium in Moscow, Russia, October 27-29, 1993.

3. Stenmark, H., and Andfossen, P.O.: " Snome WAG Pilot - A Case History", 8th European IOR Symposium in Vienna, Austria, May 15-17, 1995. Proceedings Vol. 1, 134-143.

4. Jensen, J.I., Nesteby, H., Slotte, P.A., and Berg, E.A.: "Brage WAG Pilot," RUTH Program Summary, S.M.Skjæveland, A.Skauge, L.Hinderaker, C.D.Sisk,(eds.) Norwegian Petroleum Directorate, Stavanger 1996.

5. Carlson, F.M.: "Simulation of Relative Permeability Hysteresis to the Non-Wetting Phase," SPE 10157, Presented at the 56th Annual Technical Conference and Exhibition, San Antonio, Oct. 5-7, 1981.

6. Skauge, A. and Aarra, M.: "Effect of Wettability on the Oil recovery by WAG", presented at the 7th European IOR-Symposium in Moscow, Oct 26-28, 1993, proceedings Vol 2, 452-458.

7. Skauge, A., and Larsen, J.A.: "New Approach to Model the WAG Process",Proceedings, 15 th Intemational Energy Agency Collaborative Project on Enhanced Oil Recovery, Workshop and Symposium, Bergen, Norway, 28-31 August, 1994.

8. Larsen, J. A., and Skauge, A.: "Methodology for Numerical Simulation with Cycle-Dependent Relative Permeabilities", submitted for publication in Society of Petroleum Engineers Journal, (SPEJ) 1997.

9. Zemel, B.: Tracers in the Oil Field, Developments in Petroleum Science, 43, Elsevier Sci. Publ., Amsterdam, 1995

10. Bjørnstad, T.: "Tracer Types," SPOR Monograph, S.M.Skjæveland and J.Kleppe (ed), Norwegian Petroleum Directorate, Stavanger 1992, 157-161.

11. ECL.IPSE 100 Technical Appendices, Tracer Tracking, 1995, Al39-143.

\begin{tabular}{|c|c|c|c|c|c|c|}
\hline Well & Tracers & Phase & $\begin{array}{l}\text { Time of } \\
\text { injection }\end{array}$ & well analysed & breakthrough observed & $\begin{array}{l}\text { compared } \\
\text { to expected bt }\end{array}$ \\
\hline \multirow[t]{3}{*}{$A-26$} & \multirow[t]{3}{*}{ chemical SF6 } & \multirow[t]{3}{*}{ Gas } & \multirow[t]{3}{*}{ Dec. 1994} & A-23 & Mar-95 & good \\
\hline & & & & A-25 & Sept-95 & good \\
\hline & & & & $A 01,-15,-21,-40$ & $\begin{array}{l}\text { Sept-96, Aug-96 (last } \\
\text { three) }\end{array}$ & all good \\
\hline \multirow[t]{3}{*}{ A-18 } & \multirow[t]{3}{*}{ chemical PMCH } & \multirow[t]{3}{*}{ Gas } & \multirow[t]{3}{*}{ May 1995} & A-23 & Oct-95 & good \\
\hline & & & & A-25 & Aug.-95 & poor, late in model \\
\hline & & & & $A-01,-05,-15$ & Apr, Apr, Aug 96 & poor, goodx2 \\
\hline A-26 & Tritiated water & Water & May 1995 & expected later & & \\
\hline$A-12$ & radioactive Thiocyanate & Water & July 1995 & expected later & & \\
\hline \multirow[t]{3}{*}{ A-26 } & \multirow[t]{3}{*}{ chemical PMCP } & \multirow[t]{3}{*}{ Gas } & \multirow[t]{3}{*}{ Nov. 1995} & $A-23$ & Feb-96 & good \\
\hline & & & & A-25 & Mar-96 & good \\
\hline & & & & $A-01,-15,-21$ & Sept, Aug,Aug 96 & all good \\
\hline A-18 & Tritiated Methanol & Water & April 1996 & expected later & & \\
\hline \multirow[t]{2}{*}{ A-28 } & \multirow[t]{2}{*}{ Tritiated Methane } & \multirow[t]{2}{*}{ Gas } & \multirow[t]{2}{*}{ April 1996} & A-23 & June-96 & poor \\
\hline & & & & A-15, A-21, A-40 & June-96 & poor, good, good \\
\hline A-12 & Tritiated Ethane & Gas & Oct. 1996 & expecied later & & \\
\hline$A-17$ & C-14 tagged Methanol & Water & Oct. 1996 & expected later & & \\
\hline$A-28$ & Ammonium-Thiocyanate & Water & Oct. 1996 & expected later & & \\
\hline
\end{tabular}

Table 1. Tracer injection and production 


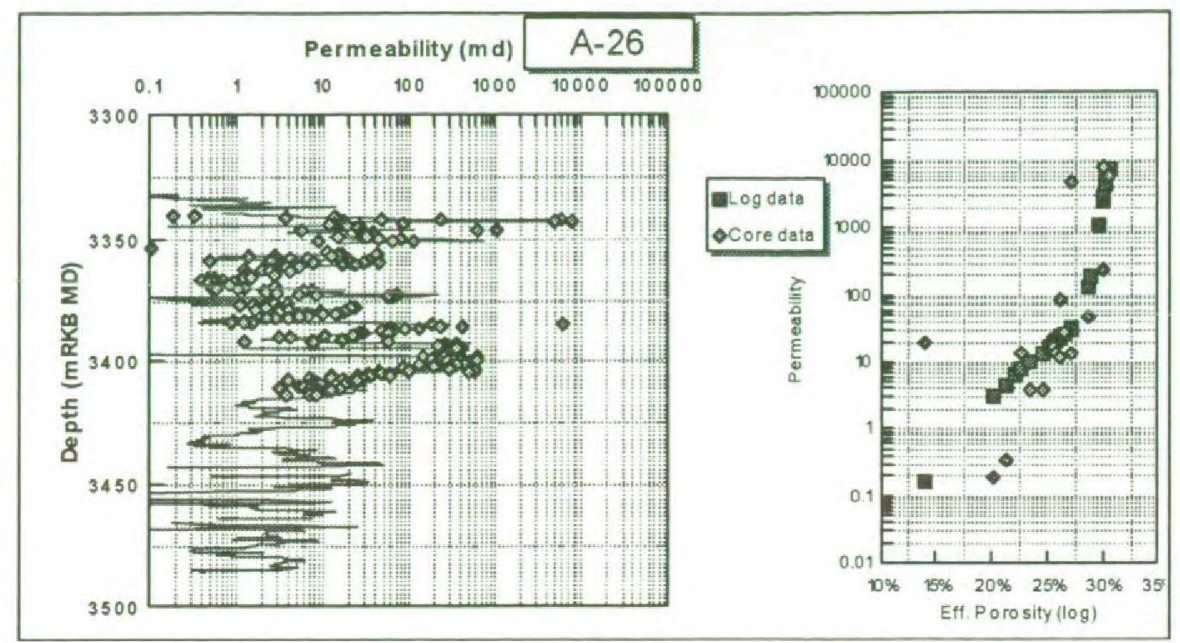

Figure 1. Permeability and porosity log of the A-26 WAG injector
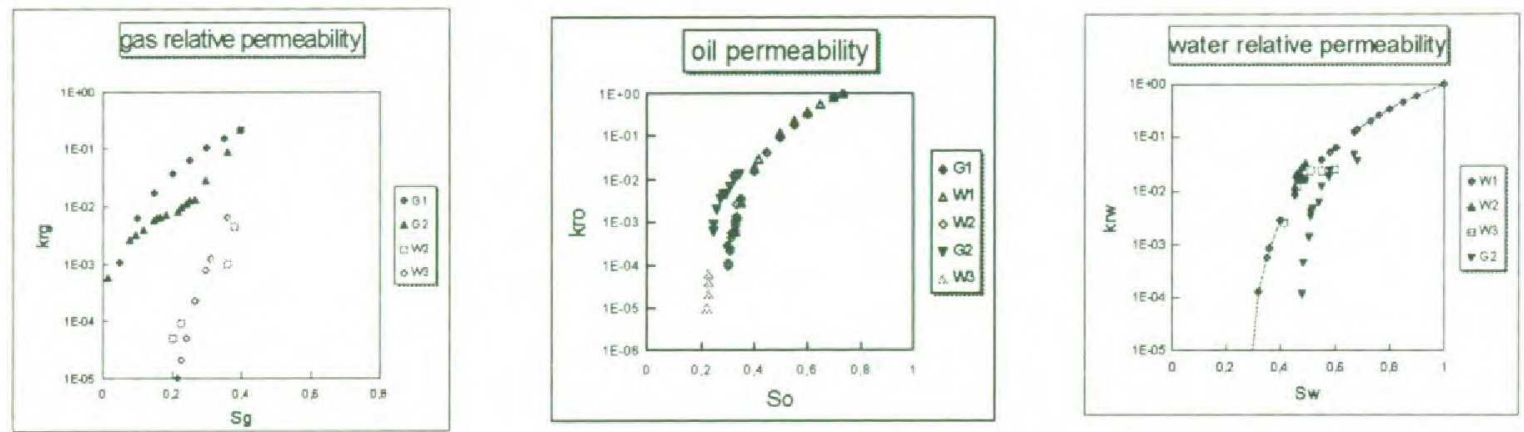

Figure 2 Relative permeability from long core displacement of Fensfjord cores at reservoir conditions

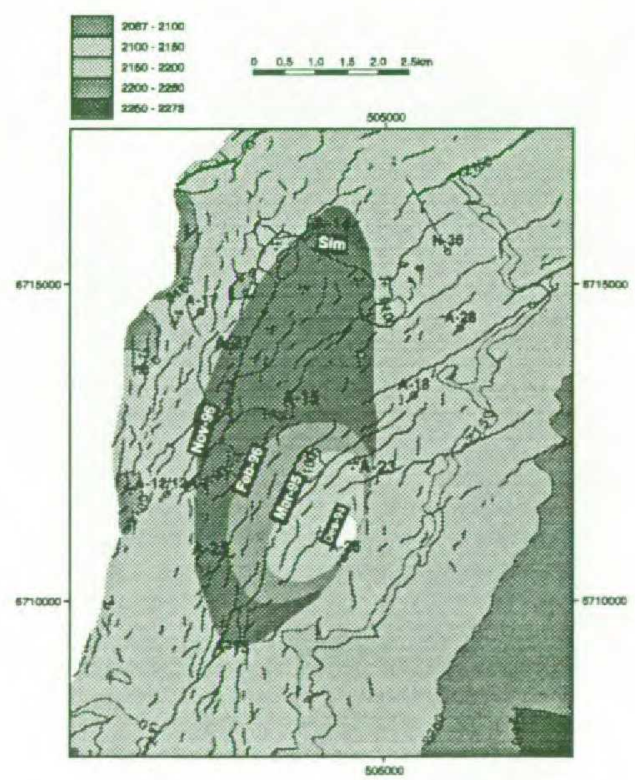

Figure 3. Observed and simulated tracer response at different times from injection of $\mathrm{SF}_{6}$ gas tracer in A-26 


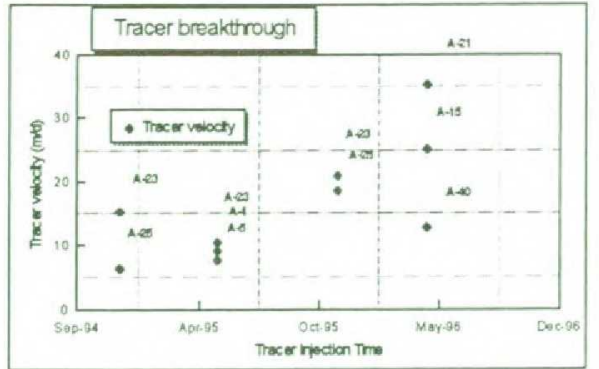

Figure 4. Field tracer velocity

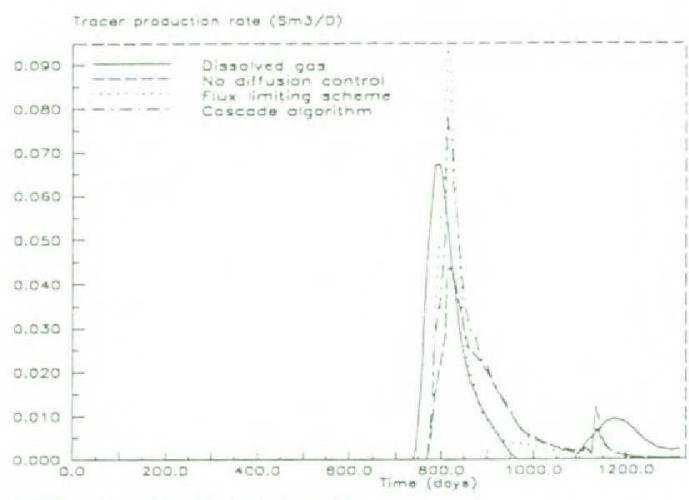

a) SFG proquction rote tor well A-23

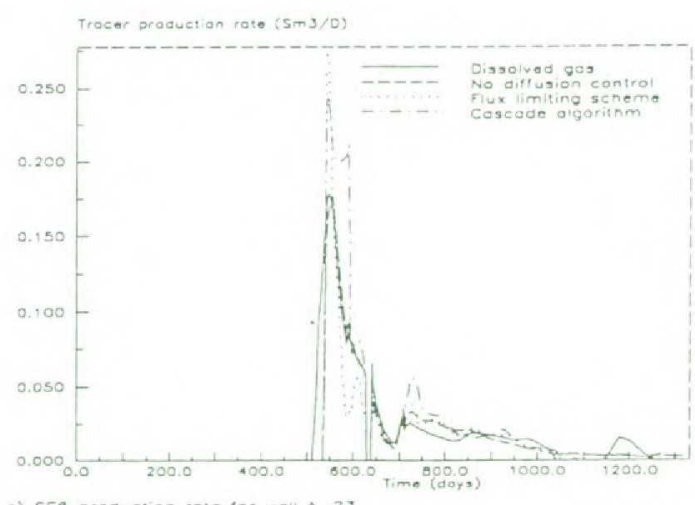

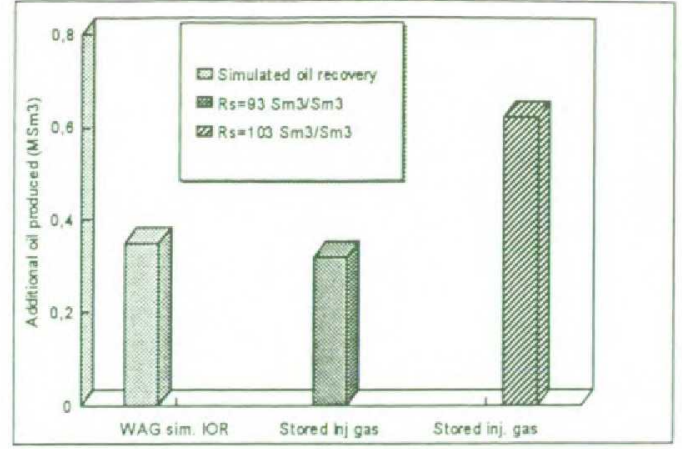

Figure 6. Field gas material balance from injected and produced gas.
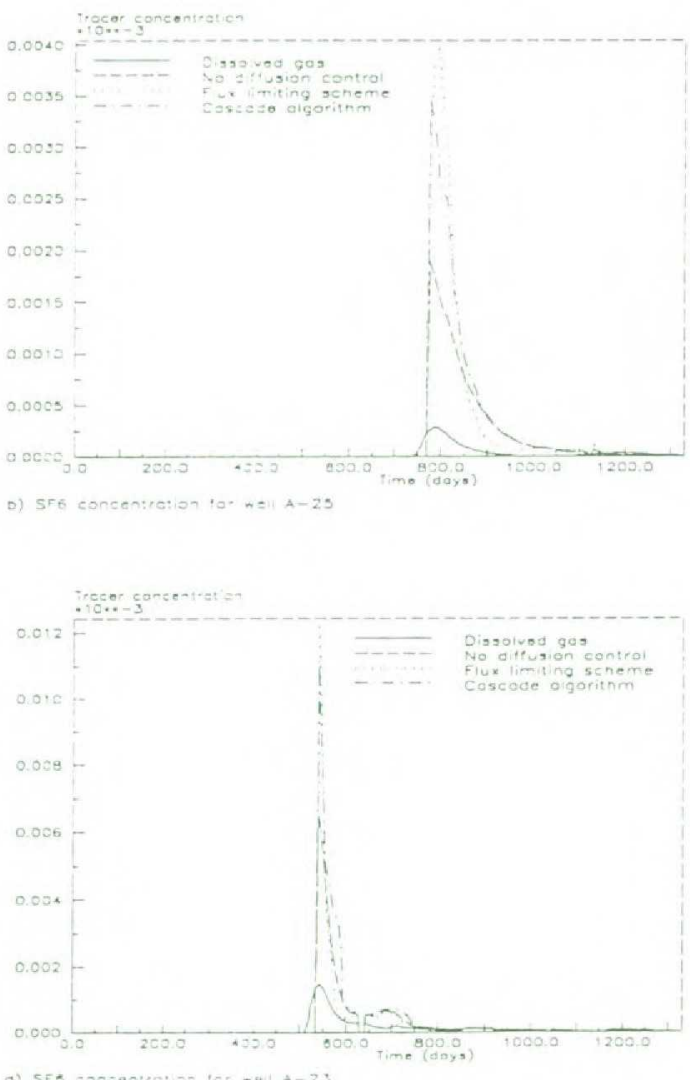

Figure 5. Simulation of produced $\mathrm{SF}_{6}$ - gas tracer in A-23 and A25 using different tracer tracking methods (dissolved gas, no diffusion control - no dissolved gas, no diff. control - flux limiting scheme - cascade algoritme) 